\title{
Genetics and age-related macular degeneration: a practical review for the clinician
}

\author{
This article was published in the following Dove Press journal: \\ Clinical Ophthalmology \\ 4 July 2016 \\ Number of times this article has been viewed
}

\author{
Stephen G Schwartz' \\ Blake M Hampton' \\ Jaclyn L Kovach' \\ Milam A Brantley J ${ }^{2}$ \\ 'Department of Ophthalmology, \\ Bascom Palmer Eye Institute, \\ University of Miami Miller School \\ of Medicine, Miami, FL, USA; \\ ${ }^{2}$ Department of Ophthalmology, \\ Vanderbilt Eye Institute, Vanderbilt \\ University Medical Center, Nashville, \\ TN, USA
}

\begin{abstract}
Age-related macular degeneration is a complex disease, with both genetic and environmental risk factors interacting in unknown ways. Currently, 52 gene variants within 34 loci have been significantly associated with age-related macular degeneration. Two wellstudied major genes are complement factor $H(C F H)$ and age-related maculopathy susceptibility 2 (ARMS2). There exist several commercially available tests that are proposed to stratify patients into high-risk and low-risk groups, as well as predict response to nutritional supplementation. However, at present, the bulk of the available peer-reviewed evidence suggests that genetic testing is more useful as a research tool than for clinical management of patients.
\end{abstract}

Keywords: age-related macular degeneration, age-related maculopathy susceptibility 2, ARMS2, complement factor $\mathrm{H}, \mathrm{CFH}$, pharmacogenetics, vascular endothelial growth factor

\section{Introduction}

Age-related macular degeneration (AMD), in both neovascular and non-neovascular forms, is a leading cause of irreversible visual loss throughout the developed world. AMD is a complex disease with both genetic and environmental risk factors. Recent advances in genetic testing have led to greatly increased understanding of these genotype-phenotype associations. This manuscript is intended to provide a concise review of the genetic basis of AMD for the practicing clinician, including a brief overview of genetic testing, risk variants associated with AMD, and risk variants associated with response to various AMD therapies (pharmacogenetics).

\section{Genetic testing}

Many diseases have one or more genetic risk factors. It is important to distinguish monogenic (single gene or Mendelian) diseases from complex genetic diseases.

Generally speaking, monogenic diseases are relatively infrequent and, by definition, caused by a single gene. The patients will often have a familial history consistent with an autosomal dominant, autosomal recessive, X-linked, or mitochondrial inheritance pattern, which may be ascertained by pedigree analysis. Frequently, multiple different single gene defects lead to a similar clinical phenotype. Examples of retinal monogenic diseases include Best vitelliform macular dystrophy (generally autosomal dominant), Leber congenital amaurosis (generally autosomal recessive), juvenile retinoschisis (generally X-linked), retinitis pigmentosa (multiple inheritance patterns), and others. Typically, individuals carrying the relevant mutation are highly likely to develop the associated disease. Therefore, there is a rationale to screen for the mutation in asymptomatic individuals, and these diseases are, at least in theory, relatively more amenable to gene therapies than are complex genetic diseases. ${ }^{1}$
Correspondence: Stephen G Schwartz Department of Ophthalmology, Bascom Palmer Eye Institute, University of Miami Miller School of Medicine, 3880 Tamiami Trail North, Naples, FL 34103, USA

Tel +l 2396593937

$\mathrm{Fax}+\mathrm{I} 2396593982$

Email sschwartz2@med.miami.edu (c) (1) (-) 2016 Schwartz et al. This work is published and licensed by Dove Medical Press Limited. The full terms of this license are available at https://www.dovepress.com/terms.php cc. hereby accept the Terms. Non-commercial uses of the work are permitted without any further permission from Dove Medical Press Limited, provided the work is properly attributed. For permission for commercial use of this work, please see paragraphs 4.2 and 5 of our Terms (https://www.dovepress.com/terms.php). 
In contrast, complex genetic diseases are more common and associated with multiple genetic and environmental risk factors. These patients will typically not have a familial history that suggests a specific inheritance pattern, and pedigree analysis is generally not helpful in this situation. Examples of retinal complex genetic diseases include diabetic retinopathy ${ }^{2}$ and AMD. Certain genetic variants, known as risk alleles or polymorphisms (as opposed to mutations), are associated with increased risk of disease, as opposed to protective alleles which are associated with decreased risk of disease. Risk alleles are not necessarily "abnormal" in the same sense as mutations, and they are typically present in at least $1 \%$ of the population. Individuals carrying one or more risk alleles may not develop the disease, while individuals lacking risk alleles may develop the disease. Therefore, from a clinical perspective, knowledge of a patient's genotype is less valuable for a complex genetic disease. Subsequently, there is no rationale to screen for these risk alleles in asymptomatic (or even affected) individuals, and these diseases are relatively less amenable to gene therapies.

Another important consideration is the fact that many published genetic association studies might be misleading. Individual reports may yield statistically significant associations, but these findings may be due to factors other than a true genetic association. These may include differences in baseline demographics of the study population, differences in clinical ascertainment, selection bias, and other factors. Therefore, it is important to validate the findings, preferably with at least one additional population.

The American Academy of Ophthalmology created a task force on genetic testing and published recommendations in $2012,{ }^{3}$ which were updated in $2014 .{ }^{4}$ These recommendations included the following: offering genetic testing to patients suspected of having a monogenic (Mendelian) disease; providing genetic counseling (or referring to a genetic counselor); avoiding direct-to-consumer genetic testing; and avoiding routine testing of complex genetic diseases such as AMD.

\section{AMD genetics}

AMD is not a monogenic disease caused by a single gene defect. Rather, it is a complex disease with both genetic and environmental risk factors. Reported environmental risk factors include age, smoking, dietary nutrients, exogenous estrogen use, and others. ${ }^{5}$ The genetic component of AMD has been estimated at $45 \%$ to $70 \%{ }^{6}$ As of this writing, 34 genetic loci, encompassing 52 gene variants, have been associated with AMD; it has been estimated that these 52 variants collectively account for about half of the heritability of the disease. ${ }^{7}$ These genes and genomic regions may be divided into high-effect, low-effect, and unknown variants. ${ }^{8}$

The two most widely studied and important loci, due to their large effect sizes and relatively high frequencies in the population, are complement factor $H(C F H)^{9-12}$ and agerelated maculopathy susceptibility 2 (ARMS2). ${ }^{13}$ ARMS2, previously termed $L O C 387715$, is in very strong linkage disequilibrium with another gene, high temperature requirement A serine peptidase 1 (HTRA1), ${ }^{14}$ and the effects of these two loci are statistically indistinguishable. It is uncertain whether ARMS2 or HTRA1 is more clinically relevant.

Significant gene-environment interactions may also occur. For example, smoking is correlated with AMD, and this association has been reported to be stronger in smokers with certain variants in nitric oxide synthase $2 A(N O S 2 A) .{ }^{15}$ Alternatively, hormone replacement therapy is negatively correlated with AMD in women, and this negative association has been reported to be stronger in women with certain ARMS2 variants. ${ }^{16}$ These results are interesting from a research perspective, but they have not been validated by other series.

It is uncertain which patients with early AMD will progress to advanced disease, including neovascular AMD and central geographic atrophy. Most risk alleles are associated with both neovascular AMD and geographic atrophy, but it has been reported recently that a variant near MMP9 (matrix metallopeptidase 9) was associated only with neovascular AMD; this is the first neovascular-specific allele identified. ${ }^{7}$

\section{AMD genetic testing in the clinic}

Because AMD is a complex genetic disease, knowledge of any one risk allele is of limited or no value to an individual patient. In contrast, a genetic risk score, calculated from known genetic and environmental risk factors, would seem to be clinically useful in advising patients about individual risk. ${ }^{17}$ The accuracy of this risk score is very important because a falsely low score may give a patient a false sense of security, while a falsely high score may expose patients to psychological stress, as well as (potentially) unnecessary examinations and perhaps medical interventions.

One measure of the accuracy of a predictive model uses a statistic known as area under the curve (AUC), in which an AUC of 0.5 indicates chance (no accuracy), an AUC of 1 is completely accurate, and an AUC of $\geq 0.75$ suggests a useful model. ${ }^{18}$ Models based on either clinical or genetic information may meet this definition of usefulness. For example, 
some clinical models, with no genetic information, have achieved AUCs of $\geq 0.76 .{ }^{19,20}$ Alternatively, some genetic risk models, with no clinical data, have achieved AUCs of $\geq 0.81 .^{21,22}$ It is reasonable to suspect that models combining clinical and genetic data may yield even more accurate information, but this is not always the case. Various combined models have reported AUCs of $\geq 0.75$. $^{23-29}$

There are currently at least three commercially available genetic AMD tests. In the US, Macula Risk PGx (ArcticDx, Toronto, ON, Canada) is ordered by a care provider. EasyDNA (Kent, UK) and Asper Biotech (Tartu, Estonia) offer direct-to-consumer genetic testing. RetnaGene (Sequenom, San Diego, CA, USA) is no longer available. 23andMe (Mountain View, CA, USA), another direct-toconsumer product, does not specifically list AMD among its offered "carrier status reports" on its website.

Macula Risk PGx analyzes 15 variants across 12 loci, as well as age, body mass index, smoking history, and educational level. The test analyzes these results and stratifies the patient into one of five "Macula Risk" categories, which are associated with varying degrees of risk of progression to advanced AMD. This laboratory also offers a second test, "Vita Risk", which uses variants at $C F H$ and $A R M S 2$ to predict response to nutritional therapy (discussed later).

A task force from the Centers for Disease Control and Prevention and the National Institutes for Health created the ACCE model to evaluate the utility of various genetic tests. ${ }^{30}$ The model considers four variables. Analytic validity measures the accuracy (sensitivity and specificity) with which the genetic information is detected. Clinical validity measures the extent to which the genetic test predicts the clinical phenotype. Clinical utility measures the ability of the test to improve clinical outcomes. And the last variable encompasses the Ethical, legal, and social implications of the test.

Therefore, the ACCE model may be applied to the Macula Risk test. This test is based on a statistical model with a reported AUC of 0.883 for 5-year progression and 0.895 for 10 -year progression, which suggests excellent analytic validity and clinical validity. ${ }^{31}$ However, one model incorporating only clinical data, with no genetic data, reported a similar AUC of $0.88,{ }^{20}$ which suggests that comparable validity may be achieved without any genetic testing whatsoever.

The clinical utility of the Macula Risk test is less certain. It would seem intuitive that identifying the patients at highest risk of progression to advanced AMD (including neovascular AMD and central geographic atrophy) would be valuable, but putting this information into clinical practice is not straightforward. One might recommend more frequent examinations for higher-risk patients, but there is little or no peer-reviewed evidence to support such a strategy. The utility of genetic testing for predicting response to nutritional supplementation will be discussed later.

The ethical, legal, and social implications of this test may be substantial, especially in terms of the psychosocial stress associated with a potentially incorrect risk assessment. Lower-risk patients may progress to advanced disease while higher-risk patients may not. These implications are intensified if one of the direct-to-consumer tests is requested by a young, asymptomatic patient. For these reasons, the American Academy of Ophthalmology task force specifically advised against testing for complex genetic diseases such as AMD and also advised avoiding direct-to-consumer genetic testing. ${ }^{4}$

\section{AMD pharmacogenetics}

AMD is treated primarily with pharmacotherapies. Patients with neovascular AMD are generally treated with antivascular endothelial growth factor (VEGF) agents, including ranibizumab (Lucentis, Genentech, South San Francisco, CA, USA), aflibercept (Eylea, Regeneron, Tarrytown, NY, USA), and bevacizumab (Avastin, Genentech). ${ }^{32}$ In addition, patients with at least intermediate AMD are typically offered nutritional supplementation as per the Age-Related Eye Disease Study (AREDS) ${ }^{33}$ and AREDS $2^{34}$ trials.

There is increasing evidence of genetic influences on response to ophthalmic medications. Such outcomes have been reported with betaxolol, ${ }^{35}$ latanoprost, ${ }^{36}$ intraocular corticosteroids, ${ }^{37}$ and other medications. ${ }^{38}$ Similarly, many small series have reported statistically significant associations between various anti-VEGF agents and variants in $\mathrm{CFH}$, ARMS2, and other genes. ${ }^{39}$ However, these findings have not been validated and major randomized clinical trials have not reported any statistically significant associations.

For example, the Comparison of AMD Treatments Trials (CATT) compared patients with neovascular AMD treated with bevacizumab or ranibizumab and reported no significant correlations between various anatomic and visual outcomes and variants in $C F H, A R M S 2, H T R A 1$, and complement factor $3(C 3) ;{ }^{40}$ endothelial PAS domaincontaining protein 1 (EPAS1); ${ }^{41}$ and VEGF A (VEGFA) and $V E G F$ receptor 2 (VEGFR2). ${ }^{42}$ Similarly, the Inhibit VEGF in Patients with Age-Related Choroidal Neovascularization (IVAN) Study also compared patients with neovascular AMD treated with bevacizumab or ranibizumab and reported no 
significant correlations between total retinal thickness on optical coherence tomography and variants in $C F H, H T R A 1 /$ ARMS2, EPAS1, and frizzled class receptor 4 (FZD4). ${ }^{43}$ Using pooled data from CATT and IVAN, no significant correlation was reported between mean change in visual acuity and VEGFR2.4

There may be more evidence supporting a pharmacogenetic relationship with AREDS nutritional supplementation to reduce risks of progression to advanced AMD (including neovascular AMD and central geographic atrophy). ${ }^{45}$ AREDS categorized AMD patients using a 1-4 scale in which categories 1 and 2 had mild disease; category 3 had at least one large $(\geq 125 \mu \mathrm{m})$ druse, extensive intermediate (63-124 $\mu \mathrm{m})$ drusen, and/or noncentral geographic atrophy; and category 4 had central geographic atrophy, neovascular AMD, and/or visual loss resulting from AMD in one eye. AREDS randomized patients to receive one of four treatments: antioxidants alone (beta-carotene, vitamin $\mathrm{C}$, and vitamin E), zinc alone (zinc plus copper), antioxidants plus zinc, and neither (placebo). In patients with category 3 or 4 AMD, treatment with antioxidants plus zinc - which subsequently became the AREDS formulation - was associated with an approximate $25 \%$ decrease in progression rates at 5 years. AREDS collected genetic information from some of the participants but did not incorporate these results into their findings. ${ }^{33}$

A retrospective subgroup analysis of 876 patients with category 3 or 4 disease from the AREDS trial subsequently compared outcomes of patients stratified by genotype at $\mathrm{CFH}$ and ARMS2. The investigators reported that all patients in this subgroup benefited from AREDS supplementation but patients with no risk alleles at $\mathrm{CFH}$ experienced significantly more favorable outcomes than did patients with two risk alleles at $C F H$. There was no association with ARMS2. Despite the statistically significant association with $C F H$, the investigators did not recommend a change in treatment (because all patients experienced some benefit) and called for additional studies to corroborate the genetic findings. ${ }^{46}$

Awh et al performed another retrospective subgroup analysis of 995 patients with category 3 disease from the same AREDS trial. They compared genotypes at $\mathrm{CFH}$ and ARMS2 with outcomes stratified by the four treatment categories (antioxidants, zinc, both, and neither). The investigators reported multiple significant genotype-phenotype correlations in which patients with certain genotypes experienced more favorable outcomes with some nutritional supplements than with others. They reported that $49 \%$ of patients analyzed had genotypes in which antioxidants plus zinc (the AREDS formulation) was associated with worse outcomes than one of the other treatment categories. The investigators concluded that a pharmacogenetic approach, in which patients were assigned to nutritional supplementation based on genotypes at $C F H$ and ARMS2, might lead to more favorable outcomes. ${ }^{47}$

In response to this publication, the AREDS investigators performed an "unplanned retrospective analysis" of a subgroup of 1,237 patients with category 3 or 4 disease from the same AREDS trial. In contrast to Awh et al, the AREDS investigators ${ }^{48}$ reported no significant associations between progression rates stratified by nutritional supplementation and genotypes at $C F H$ and $A R M S 2$.

Awh et al then published yet another retrospective subgroup analysis of 989 patients with category 3 or 4 disease from the original AREDS trial. They again reported a complex relationship between $C F H, A R M S 2$, and outcomes stratified by nutritional supplementation. They concluded that "most" patients would benefit from either no supplementation at all or a supplementation other than the AREDS formulation (antioxidants plus zinc). They noted the lack of an available replication sample with which to validate their findings, but they reiterated their recommendation that patients be offered genotype-directed nutritional supplementation. ${ }^{49}$

The AREDS investigators then attempted to validate the findings in the two reports by Awh et al. Because Awh et al analyzed only a subset of the patients in the original AREDS trial, the AREDS investigators hypothesized that the remaining (nonanalyzed) patients could be similarly studied, which could represent a replication sample. The investigators then identified 526 patients from the original AREDS trial not previously analyzed by Awh et al and reported that the findings were not replicated. The investigators specifically reported that, among the 526 patients analyzed, the AREDS formulation (antioxidants plus zinc) was the most beneficial nutritional supplement for all genetic subtypes studied. ${ }^{50}$

To date, there has not yet been a prospective clinical trial published that specifically studied genotype-phenotype relationships with respect to nutritional supplementation. There have been five separate retrospective subgroup analyses of the initial AREDS study data which have led to conflicting conclusions. One study reported a significant difference in progression rates among patients with risk variants at $\mathrm{CFH}$ but did not recommend any change in standard clinical treatment. ${ }^{46}$ Two studies by Awh et $\mathrm{al}^{47,49}$ reported a complex relationship between risk variants at $C F H, A R M S 2$ and 
clinical outcomes and recommended using genotype-directed nutritional therapy in order to improve overall outcomes. Two studies by the AREDS investigators ${ }^{48,50}$ reported no significant differences, including an attempt to replicate the findings of Awh et al.

How should the practicing clinician interpret these conflicting studies? Certain general principles seem appropriate. First, a randomized clinical trial which was designed to answer a specific question offers a higher level of evidence than does a retrospective subgroup analysis from the same trial that attempts to answer a separate question (in this case, whether genetic information can be used to guide nutritional therapy). ${ }^{51}$

Second, as discussed earlier, genetic association studies may be misleading. Inadvertent selection bias may lead to statistically significant correlations that are not "true" in a clinical sense; this is especially likely as the number of individual comparisons increases. For example, many small series have reported statistically significant pharmacogenetic associations with respect to anti-VEGF therapy, but large clinical trials specifically attempting to uncover these relationships have found no such associations. Therefore, it is generally advisable to replicate the findings with a second (unrelated) study population before recommending largescale changes to clinical practices. ${ }^{52}$

Third, because AMD is a complex disease, with both genetic and environmental risk factors that interact in unknown ways, it is perhaps not surprising that analyzing risk variants at only two loci ( $C F H$ and $A R M S 2)$ yields limited information. There exist many patients with risk variants at both loci who do not develop AMD, just as there exist many patients with no risk variants at either locus who do develop AMD. Therefore, testing only ARMS 2 and $C F H$ may yield misleading results that are not useful clinically. ${ }^{53}$

\section{Conclusion}

In patients with monogenic diseases, knowledge of an individual patient's genotype is important to confirm the diagnosis and to offer prognostic information. In contrast, AMD is a complex disease with both genetic and environmental risk factors. There is an increasing body of literature which gives insight into risk variants at $C F H, A R M S 2$, and many other loci, but at present there is not convincing evidence that genetic testing is beneficial in the routine clinical care of patients with AMD. As additional clinical trials are performed, perhaps the situation will change. But for now, genetic testing is more useful as a research strategy than in day-to-day clinical management.

\section{Acknowledgments}

This study was partially supported by (US) National Institutes of Health Center Core Grant P30EY014801 and by an unrestricted grant from Research to Prevent Blindness, New York, NY, USA.

\section{Disclosure}

The authors report no conflicts of interest in this work.

\section{References}

1. Bainbridge JW, Mehat MS, Sundaram V, et al. Long-term effect of gene therapy on Leber's congenital amaurosis. $N$ Engl J Med. 2015; 372(20):1887-1897.

2. Hampton BM, Schwartz SG, Brantley MA Jr, Flynn HW Jr. Update on genetics and diabetic retinopathy. Clin Ophthalmol. 2015;9:2175-2193.

3. Stone EM, Aldave AJ, Drack AV, et al. Recommendations for genetic testing of inherited eye diseases: report of the American Academy of Ophthalmology task force on genetic testing. Ophthalmology. 2012; 119(11):2408-2410.

4. Stone EM, Aldave AJ, Drack AV, et al. Recommendations of the American Academy of Ophthalmology task force on genetic testing. Available from: http://www.aao.org/clinical-statement/recommendations-genetictesting-of-inherited-eye-d. Accessed June 23, 2016.

5. Clemons TE, Milton RC, Klein R, Seddon JM, Ferris FL 3rd; Age-Related Eye Disease Study Research Group. Risk factors for the incidence of Advanced Age-Related Macular Degeneration in the Age-Related Eye Disease Study (AREDS): AREDS report no. 19. Ophthalmology. 2005;112(4):533-539.

6. Seddon JM, Cote J, Page WF, Aggen SH, Neale MC. The US twin study of age-related macular degeneration: relative roles of genetic and environmental influences. Arch Ophthalmol. 2005;123(3):321-327.

7. Fritsche LG, Igl W, Bailey JN, et al. A large genome-wide association study of age-related macular degeneration highlights contributions of rare and common variants. Nat Genet. 2016;48(2):134-143.

8. Cooke Bailey JN, Sobrin L, Pericak-Vance MA, Haines JL, Hammond CJ, Wiggs JL. Advances in the genomics of common eye diseases. Hum Mol Genet. 2013;22(R1):R59-R65.

9. Klein RJ, Zeiss C, Chew EY, et al. Complement factor H polymorphism in age-related macular degeneration. Science. 2005;308(5720): 385-389.

10. Haines JL, Hauser MA, Schmidt S, et al. Complement factor $\mathrm{H}$ variant increases the risk of age-related macular degeneration. Science. 2005; 308(5720):419-421.

11. Edwards AO, Ritter R 3rd, Abel KJ, Manning A, Panhuysen C, Farrer LA. Complement factor $\mathrm{H}$ polymorphism and age-related macular degeneration. Science. 2005;308(5720):421-424.

12. Hageman GS, Anderson DH, Johnson LV, et al. A common haplotype in the complement regulator factor $\mathrm{H}(\mathrm{HF} 1 / \mathrm{CFH})$ predisposes individuals to age-related macular degeneration. Proc Natl Acad Sci U S A 2005;102(20):7227-7232.

13. Jakobsdottir J, Conley YP, Weeks DE, Mah TS, Ferrell RE, Gorin MB. Susceptibility genes for age-related maculopathy on chromosome 10q26. Am J Hum Genet. 2005;77(3):389-407.

14. Yang Z, Camp NJ, Sun H, et al. A variant of the HTRAl gene increases susceptibility to age-related macular degeneration. Science. 2006; 314(5801):992-993.

15. Ayala-Haedo JA, Gallins PJ, Whitehead PL, et al. Analysis of single nucleotide polymorphisms in the NOS2A gene and interaction with smoking in age-related macular degeneration. Ann Hum Genet. 2010;74(3): 195-201.

16. Edwards DR, Gallins P, Polk M, et al. Inverse association of female hormone replacement therapy with age-related macular degeneration and interactions with ARMS2 polymorphisms. Invest Ophthalmol Vis Sci. 2010;51(4):1873-1879. 
17. Cooke Bailey JN, Hoffman JD, Sardell RJ, ScottWK, Pericak-Vance MA, Haines JL. The application of genetic risk scores in age-related macular degeneration: a review. J Clin Med. 2016;5(3):31.

18. Janssens AC, Moonesinghe R, Yang Q, Steyerberg EW, van Duijn CM, Khoury MJ. The impact of genotype frequencies on the clinical validity of genomic profiling for predicting common chronic diseases. Genet Med. 2007;9(8):528-535.

19. Ying GS, Maguire MG; Complications of Age-Related Macular Degeneration Prevention Trial Research Group. Development of a risk score for geographic atrophy in Complications of the Age-Related Macular Degeneration Prevention Trial. Ophthalmology. 2011;118(2):332-338.

20. Chiu CJ, Mitchell P, Klein R, et al. A risk score for the prediction of advanced age-related macular degeneration: development and validation in 2 prospective cohorts. Ophthalmology. 2014;121(7):1421-1427.

21. Hageman GS, Gehrs K, Lejnine S, et al. Clinical validation of a genetic model to estimate the risk of developing choroidal neovascular agerelated macular degeneration. Hum Genomics. 2011;5(5):420-440.

22. Grassmann F, Fritsche LG, Keilhauer CN, Heid IM, Weber BH. Modelling the genetic risk in age-related macular degeneration. PLoS One. 2012;7(5):e37979.

23. Klein ML, Francis PJ, Ferris FL 3rd, Hamon SC, Clemons TE. Risk assessment model for development of advanced age-related macular degeneration. Arch Ophthalmol. 2011;129(12):1543-1550.

24. Spencer KL, Olson LM, Schnetz-Boutaud N, et al. Using genetic variation and environmental risk factor data to identify individuals at high risk for age-related macular degeneration. PLoS One. 2011;6(3):e17784.

25. Chen Y, Zeng J, Zhao C, et al. Assessing susceptibility to age-related macular degeneration with genetic markers and environmental factors. Arch Ophthalmol. 2011;129(3):344-351.

26. Seddon JM, Reynolds R, Yu Y, Daly MJ, Rosner B. Risk models for progression to advanced age-related macular degeneration using demographic, environmental, genetic, and ocular factors. Ophthalmology. 2011;118(11):2203-2211.

27. Seddon JM, Reynolds R, Yu Y, Rosner B. Validation of a prediction algorithm for progression to advanced macular degeneration subtypes. JAMA Ophthalmol. 2013;131(4):448-455.

28. Buitendijk GH, Rochtchina E, Myers C, et al. Prediction of age-related macular degeneration in the general population: the Three Continent AMD Consortium. Ophthalmology. 2013;120(12):2644-2655.

29. Seddon JM, Silver RE, Kwong M, Rosner B. Risk prediction for progression of macular degeneration: 10 common and rare genetic variants, demographic, environmental, and macular covariates. Invest Ophthalmol Vis Sci. 2015;56(4):2192-2202.

30. Burke W, Atkins D, Gwinn M, et al. Genetic test evaluation: information needs of clinicians, policy makers, and the public. Am JEpidemiol. 2002; 156(4):311-318

31. Yu Y, Reynolds R, Rosner B, Daly MJ, Seddon JM. Prospective assessment of genetic effects on progression to different stages of agerelated macular degeneration using multistate Markov models. Invest Ophthalmol Vis Sci. 2012;53(3):1548-1556.

32. Kovach JL, Schwartz SG, Flynn HW Jr, Scott IU. Anti-VEGF treatment strategies for wet AMD. J Ophthalmol. 2012;2012:786870.

33. Age-Related Eye Disease Study Group. A randomized, placebo-controlled, clinical trial of high-dose supplementation with vitamins $\mathrm{C}$ and $\mathrm{E}$, betacarotene, and zinc for age-related macular degeneration and vision loss: AREDS report no. 8. Arch Ophthalmol. 2001;119(10):1417-1436.

34. Age-Related Eye Disease Study 2 Research Group. Lutein + zeaxanthin and omega-3 fatty acids for age-related macular degeneration: the Age-Related Eye Disease Study 2 (AREDS2) randomized clinical trial. JAMA. 2013;309(19):2005-2015.

35. Schwartz SG, Puckett BJ, Allen RC, Castillo IG, Leffler CT. Beta1adrenergic receptor polymorphisms and clinical efficacy of betaxolol hydrochloride in normal volunteers. Ophthalmology. 2005;112(12): 2131-2136.

36. Sakurai M, Higashide T, Ohkubo S, Takeda H, Sugiyama K. Association between genetic polymorphisms of the prostaglandin F2 $\alpha$ receptor gene, and response to latanoprost in patients with glaucoma and ocular hypertension. Br J Ophthalmol. 2014;98(4):469-473.
37. Jeong $\mathrm{S}$, Patel $\mathrm{N}$, Edlund $\mathrm{CK}$, et al. Identification of a novel mucin gene HCG22 associated with steroid-induced ocular hypertension. Invest Ophthalmol Vis Sci. 2015;56(4):2737-2748.

38. Shastry BS. Pharmacogenetics in ophthalmology. Discov Med. 2011; 12(63):159-167.

39. Schwartz SG, Brantley MA Jr. Pharmacogenetics and age-related macular degeneration. J Ophthalmol. 2011;2011:252549.

40. Hagstrom SA, Ying GS, Pauer GJ, et al; Comparison of AMD Treatments Trials Research Group. Pharmacogenetics for genes associated with age-related macular degeneration in the Comparison of AMD Treatments Trials (CATT). Ophthalmology. 2013;120(3):593-599.

41. Hagstrom SA, Ying GS, Pauer GJ, Huang J, Maguire MG, Martin DF; CATT Research Group. Endothelial PAS domain-containing protein 1 (EPAS1) gene polymorphisms and response to anti-VEGF therapy in the Comparison of AMD Treatments Trials (CATT). Ophthalmology. 2014;121(8):1663-1664.

42. Hagstrom SA, Ying GS, Pauer GJ, et al; Comparison of Age-Related Macular Degeneration Treatments Trials (CATT) Research Group. VEGFA and VEGFR2 gene polymorphisms and response to antivascular endothelial growth factor therapy: Comparison of Age-Related Macular Degeneration Treatments Trials (CATT). JAMA Ophthalmol. 2014;132(5):521-527.

43. Lotery AJ, Gibson J, Cree AJ; Alternative Treatments to Inhibit VEGF in Patients with Age-Related Choroidal Neovascularisation (IVAN) Study Group. Pharmacogenetic associations with vascular endothelial growth factor inhibition in participants with neovascular age-related macular degeneration in the IVAN Study. Ophthalmology. 2013;120(12):2637-2643

44. Hagstrom SA, Ying GS, Maguire MG, et al. VEGFR2 polymorphisms and response to anti-vascular endothelial growth factor therapy in age-related macular degeneration. Ophthalmology. 2015; 122(8): 1563-1568.

45. Hampton BM, Kovach JL, Schwartz SG. Pharmacogenetics and nutritional supplementation in age-related macular degeneration. Clin Ophthalmol. 2015;9:873-876.

46. Klein ML, Francis PJ, Rosner B, et al. CFH and LOC387715/ARMS2 genotypes and treatment with antioxidants and zinc for age-related macular degeneration. Ophthalmology. 2008;115(6):1019-1025.

47. Awh CC, Lane AM, Hawken S, Zanke B, Kim IK. CFH and ARMS2 genetic polymorphisms predict response to antioxidants plus zinc in patients with age-related macular degeneration. Ophthalmology. 2013; 120(11):2317-2323.

48. Chew EY, Klein ML, Clemons TE, et al; Age-Related Eye Disease Study Research Group. No clinically significant association between $\mathrm{CFH}$ and ARMS2 genotypes and response to nutritional supplements: AREDS report number 38. Ophthalmology. 2014;121(11):2173-2180.

49. Awh CC, Hawken S, Zanke BW. Treatment response to antioxidants and zinc based on CFH and ARMS2 genetic risk allele number in the AgeRelated Eye Disease Study. Ophthalmology. 2015;122(1):162-169.

50. Chew EY, Klein ML, Clemons TE, Agron E, Abecasis GR. Genetic testing in persons with age-related macular degeneration and the use of the AREDS supplements: to test or not to test? Ophthalmology. 2015; 122(1):212-215.

51. Schwartz SG. Re: Awh CC, Lane AM, Hawken S, Zanke B, Kim IK. $\mathrm{CFH}$ and ARMS2 genetic polymorphisms predict response to antioxidants and zinc in patients with age-related macular degeneration (Ophthalmology. 2013;120(11):2317-2323). Ophthalmology. 2014; 121(8): 38 .

52. Wittes J, Musch DC. Should we test for genotype in deciding on AgeRelated Eye Disease Study supplementation? Ophthalmology. 2015; 122(1):3-5.

53. Stone EM. Genetic testing for age-related macular degeneration: not indicated now. JAMA Ophthalmol. 2015;133(5):598-600. 


\section{Publish your work in this journal}

Clinical Ophthalmology is an international, peer-reviewed journal covering all subspecialties within ophthalmology. Key topics include: Optometry; Visual science; Pharmacology and drug therapy in eye diseases; Basic Sciences; Primary and Secondary eye care; Patien Safety and Quality of Care Improvements. This journal is indexed on

Submit your manuscript here: http://www.dovepress.com/clinical-ophthalmology-journal
Dovepress

PubMed Central and CAS, and is the official journal of The Society of Clinical Ophthalmology (SCO). The manuscript management system is completely online and includes a very quick and fair peer-review system, which is all easy to use. Visit http://www.dovepress.com/ testimonials.php to read real quotes from published authors. 